\title{
Cuidado da equipe médica e multiprofissional no Tratamento do Idoso Hospitalizado
}

\author{
Oliveira, N.A.; Gulla, A.C.; Coutinho, C.C.;
}

Apresentador: Naila Albertina de Oliveira

\section{Resumo}

Introdução: A população mundial com o aumento da qualidade de vida houve um número crescente de idosos. Tal cenário demonstra que o envelhecimento se tornou uma discussão de âmbito socioeconômico e principalmente sanitário. Houve essa mudança do aumento da população idosa nas últimas duas décadas e tal mudança do perfil demográfico da população diminuíram as doenças infecto-contagiosas, no entanto as doenças crônico-degenerativas aumentaram significativamente. Políticas públicas de saúde voltadas para a população idosa não tem uma estruturação adequada para o atendimento dos problemas de saúde mental dessa população. No Brasil a transição demográfica e epidemiológica, não foi simultânea ao desenvolvendo programas de melhoria nas condições sociais e de assistência integral à população idosa. $\mathrm{O}$ objetivo principal do estudo baseou-se em evidenciar a importância da assistência multidisciplinar da equipe médica com a equipe de saúde no tratamento do idoso hospitalizado com o intuito de proporcionar o cuidado à saúde do geronte no diagnóstico, tratamento e prevenção de sequelas. A metodologia utilizada foi à avaliação dos idosos hospitalizados em um hospital da cidade de campinas. Essa avaliação foi realizada a partir dos dados dos prontuários, das anotações médicas e relatos da equipe de saúde frente à assistência e aos cuidados prestados aos 20 idosos hospitalizados, os quais foram avaliados do momento da internação até a alta hospitalar. Os idosos avaliados no estudo demonstraram sintomatologia para a depressão, sendo que $29 \%$ apresentaram sinais como apatia, desesperança, $5 \%$ relataram que já tiveram a ideia de suicídio, e $66 \%$ apresentaram diagnóstico de depressão de acordo com relato do prontuário médico, e $50 \%$ dos idosos faziam uso de anti-depressivos e/ou antiansiolíticos. Conclui-se que com a assistência prestada ao idoso atualmente no cenário médico juntamente a equipe de saúde há um déficit de profissionais capacitados para o atendimento na área de gerontologia e geriatria, e que os profissionais de saúde devem se capacitar continuamente na área de saúde do idoso, prevenindo subsequentes internações, resistência antimicrobiana, garantindo a segurança do idoso hospitalizado.

\section{Referência:}

Oliveira, N.A.; Gulla, A.C.; Coutinho, C.C.;. Cuidado da equipe médica e multiprofissional no Tratamento do Idoso Hospitalizado. In: II Congresso Brasileiro de Medicina Hospitalar - II CBMH [= Blucher Medical Proceedings, vol.1, num.5] São Paulo: Editora Blucher, 2014. p.76

DOI 10.5151/medpro-II-cbmh-073 